\title{
Profundidade de localização do herbicida imazetapir + imazapique no solo sobre a fitotoxicidade em de plantas de arroz não resistente
}

\author{
Depth of placement of the herbicide imazethapyr + imazapic in soil profile on \\ non-tolerant rice injury
}

\section{Angela Da Cas Bundt ${ }^{\mathrm{I}}$ Luis Antonio de AvilaII Dirceu Agostinetto ${ }^{\mathrm{II}}$ Marcos André Nohatto ${ }^{\mathrm{I}}$ Kelen Müller Souto ${ }^{\mathrm{III}}$ Scott Allen Senseman ${ }^{\mathrm{IV}}$}

\section{RESUMO}

Os herbicidas imazetapir e imazapique, usados em cultivares de arroz Clearfield ${ }^{\circledR}$, possuem alta persistência e mobilidade no solo, ocasionando danos em genótipos de arroz não resistentes cultivados em rotação. Tais herbicidas podem lixiviar e atingir maiores profundidades ao longo do perfil. Esse posicionamento em profundidade pode ser um fator de seletividade e explicar parcialmente os diferentes resultados encontrados na literatura sobre o efeito residual do herbicida no solo. $O$ objetivo do estudo foi avaliar o efeito da profundidade de localização no solo e da mistura formulada pelos herbicidas imazetapir e imazapique ( 75 e $25 \mathrm{~g}$ e.a. $\left.\mathrm{L}^{-1}\right) \mathrm{na}$ fitotoxicidade em genótipos de arroz não resistentes. Nesse sentido, foram conduzidos dois experimentos em solo com $15 \%$ de argila e 1,2\% de matéria orgânica, em casa-devegetação, no campus da Universidade Federal de Pelotas (UFPel), em Pelotas, Rio Grande do Sul (RS). O experimento I consistiu de estudo preliminar visando a determinar a profundidade máxima de localização do herbicida no solo que causa danos ao arroz não resistente, e o herbicida foi alocado nas profundidades de 0, 5, 10, 20, 30, 50 e $70 \mathrm{~cm}$. O experimento II também consistiu na alocação do herbicida em profundidades ao longo do perfil do solo de 3, 6, 9, 12, 15 e $18 \mathrm{~cm}$. As variáveis analisadas foram fitotoxicidade, massa da matéria seca e estatura das plantas. O herbicida resultante da mistura formulada de imazetapir com imazapique localizado próximo à superfície do solo causa danos intensos em plantas de arroz não resistente, porém, quando alocado em profundidades maiores que $20 \mathrm{~cm}$ da superfície do solo, não prejudica o desenvolvimento de genótipos de arroz não resistentes a essa mistura de herbicidas.
Palavras-chave: lixiviação, Oryza sativa, persistência, profundidade de localização.

\begin{abstract}
The herbicides imazethapyr and imazapic, used in Clearfield ${ }^{\circledR}$ rice, have high mobility and persistence in the soil, causing injury to non-resistant rice grown in rotation. These herbicides can leach and reach greater depths along the profile. This positioning can be a in-depth selectivity factor and partially explain the different results found in literature about carryover of imidazolines. To understand this effect, this study had the objective of to evaluate the effect of the positioning of the mixture of imazethapyr and imazapic $\left(75 \mathrm{~g}\right.$ ai $\mathrm{L}^{-1}$ and $25 \mathrm{~g}$ ai $\mathrm{L}^{-1}$ ) on the injury to non-resistant rice crop. Two experiments were carried out in soil with $15 \%$ clay and $1.2 \%$ organic matter in a greenhouse at the Universidade Federal de Pelotas, Pelotas, RS, Brazil. Experiment I consisted of a preliminary study to verify the location depth of the herbicide in the soil profile that causes injury to rice non-tolerant rice, and the herbicides has been allocated at depths of 0, 5, 10, 20, 30,50 e $70 \mathrm{~cm}$. Experiment II also consisted in the allocation of herbicide at depths in the soil profile of 3, 6, 9, 12, 15 and $18 \mathrm{~cm}$. The variables were visual plant injury, plant shoot dry weight and plant height. The formulated mixture of imazethapyr + imazapic located near the soil surface cause injury to non resistant rice plants but when allocated at depths greater than $20 \mathrm{~cm}$ of the soil surface does not affect the development of non-resistant rice .
\end{abstract}

Key words: leaching, persistence, Oryza sativa, depth location.

'Programa de Pós-graduação em Fitossanidade, Universidade Federal de Pelotas (UFPel), Pelotas, RS, Brasil.

IDepartamento de Fitossanidade, Faculdade de Agronomia Eliseu Maciel, UFPel, Campus Universitário, CP 354, 96010-900, Pelotas, RS, Brasil. E-mail: laavilabr@gmail.com.*Autor para correspondência.

IIPrograma de Pós-graduação em Agronomia, Universidade Federal de Santa Maria, Santa Maria, RS, Brasil.

${ }^{\mathrm{IV}}$ Department of Soil and Crop Sciences, Texas A\&M University, College Station, Texas, EUA. 


\section{INTRODUÇÃO}

O sistema Clearfield ${ }^{\boxplus}$ de produção de arroz irrigado é usado em mais de 500 mil hectares no Rio Grande do Sul (IRGA, 2008), por ser eficiente estratégia para o controle de arroz-vermelho (SANTOS et al., 2007). Os herbicidas imazetapir e imazapique são utilizados nesse sistema e pertencem ao grupo químico das imidazolinonas, as quais possuem alta persistência no solo, podendo causar danos em culturas sensíveis ou cultivares de arroz não resistentes a esses herbicidas, quando semeadas em sucessão ou rotação (MARCHESAN et al., 2010).

Em relação à fitotoxicidade em genótipos de arroz irrigado não resistentes, existem contradições quanto aos resultados encontrados por diferentes autores (VILLA et al., 2006; KRAEMER et al., 2009; MARCHESAN et al., 2010), as quais podem ser explicadas por diversos fatores, como aqueles relacionados ao manejo da lavoura (KRAEMER et al., 2009), à textura do solo e à precipitação pluvial e/ou irrigação. Esses fatores influenciam diretamente a mobilidade do herbicida no perfil do solo, sendo este um aspecto importante na disponibilidade do herbicida para as plantas. Resultados de pesquisas demonstraram que, após um ano da aplicação de imazetapir, a maior concentração do herbicida foi observada até $20 \mathrm{~cm}$ de profundidade em solo de várzea com 2,3\% de matéria orgânica e 26\% de argila (KRAEMER et al., 2009) ou $40 \mathrm{~cm}$ após três anos de cultivos (HOLLAWAY et al., 2006).

Um aspecto importante da lixiviação de herbicidas refere-se à seletividade por posicionamento no solo. Um exemplo dessa seletividade foi observado por ZHANG et al. (2000), que verificaram que o arroz semeado em maiores profundidades desenvolveram coleóptilos mais longos e sistema radicular mais profundo, estando exposto à maior absorção de imazetapir. Assim, a lixiviação desse herbicida para locais distantes das radículas das plântulas, na fase inicial da germinação, pode ser uma eficiente forma de seletividade por posicionamento do herbicida no solo. Em vista do exposto, o objetivo deste trabalho foi avaliar o posicionamento do herbicida composto pela mistura formulada de imazetapir e imazapique $\left(75+25 \mathrm{~g}\right.$ e.a. $\left.\mathrm{L}^{-1}\right)$ no perfil do solo sobre o desenvolvimento inicial de genótipos de arroz não resistente.

\section{MATERIAL E MÉTODOS}

Foram conduzidos dois experimentos em casa-de-vegetação, na Faculdade de Agronomia Eliseu Maciel (FAEM) da Universidade Federal de Pelotas
(UFPel). O experimento I foi realizado no ano agrícola de 2008/09 e consistiu de estudo exploratório para a realização do experimento II. Foi utilizado o delineamento inteiramente casualizado, com quatro repetições, em que os tratamentos consistiram no posicionamento do equivalente-ácido de $0,5 \mathrm{~L} \mathrm{ha}^{-1}$ $(6,28 \mu \mathrm{L}$ por unidade experimental) do herbicida composto pela mistura formulada de imazetapir e imazapique ( 75 e $25 \mathrm{~g}$ e.a. $\left.\mathrm{L}^{-1}\right)$, em diferentes profundidades no solo $(0,5,10,20,30,50$ e $70 \mathrm{~cm})$, além do tratamento sem a aplicação dessa mistura de herbicidas (testemunha).

Para a condução do experimento, foram utilizados tubos de PVC (cloreto de polivinil) de $80 \mathrm{~cm}$ de comprimento e $20 \mathrm{~cm}$ de diâmetro, com a base vedada por tampa (CAP de PVC) e impermeabilizada com silicone líquido para evitar perdas de água. $\mathrm{O}$ solo de várzea utilizado foi coletado no horizonte $\mathrm{A}$ do Centro Agronômico da Palma (CAP) pertencente à UFPel. Esse solo é classificado como Planossolo Hidromórfico Eutrófico Solódico (Unidade de Mapeamento Pelotas), com as seguintes características: $\mathrm{pH}$ água $(1: 1)=5,1 ; \mathrm{CTC} \mathrm{pH} 7=5,4 \mathrm{cmolc}$ $\mathrm{dm}^{-3}$; matéria orgânica $=1,2 \%$; argila $=15 \%$; textura $=4$; $\mathrm{Ca}=1,8 \mathrm{cmolc} \mathrm{dm}^{-3} ; \mathrm{Mg}=1 \mathrm{cmolc} \mathrm{dm}^{-3} ; \mathrm{Al}=0,2 \mathrm{cmol} \mathrm{cdm}^{-3}$; $\mathrm{P}=4,3 \mathrm{mg} \mathrm{dm}^{-3}$; e $\mathrm{K}=30 \mathrm{mg} \mathrm{dm}^{-3}$. O solo, após destorroado e peneirado, foi transferido para tubos de PVC até à profundidade correspondente de alocação do herbicida no solo. Em cada tubo, foi colocada água com a finalidade de obter uma umidade do solo acima da sua capacidade de campo para que este pudesse sedimentar na profundidade necessária para o tratamento e evitar a lixiviação do herbicida pelas irrigações durante a condução do experimento.

Uma amostra de $250 \mathrm{~g}$ de solo foi tratada com a quantidade correspondente a $0,5 \mathrm{~L} \mathrm{ha}^{-1}(6,28 \mu \mathrm{L}) \mathrm{da}$ mistura formulada, diluído em $20 \mathrm{ml}$ de água destilada. $\mathrm{O}$ solo tratado ficou em repouso por $24 \mathrm{~h}$, para que houvesse equilíbrio de sorção dos herbicidas no solo, sendo em seguida transferido aos tubos de PVC, aplicando-se em camada uniforme na profundidade desejada e imediatamente foram preenchidos com solo até completar a altura de $70 \mathrm{~cm}$ no tubo (Figura $1 \mathrm{~A}$ ).

Logo após a aplicação do solo tratado com o herbicida nas unidades experimentais, foram semeadas, na profundidade de $1,0 \mathrm{~cm}, 15$ sementes da cultivar 'IRGA 417', genótipo de arroz não resistente aos herbicidas imazetapir e imazapique. Após a emergência das plântulas, realizou-se o desbaste, sendo deixadas oito plantas. A partir do estádio de quatro folhas, foi realizada inundação, onde foi mantida lâmina de água de $10 \mathrm{~cm}$ de altura durante a condução do experimento. A adubação de base foi feita no momento 


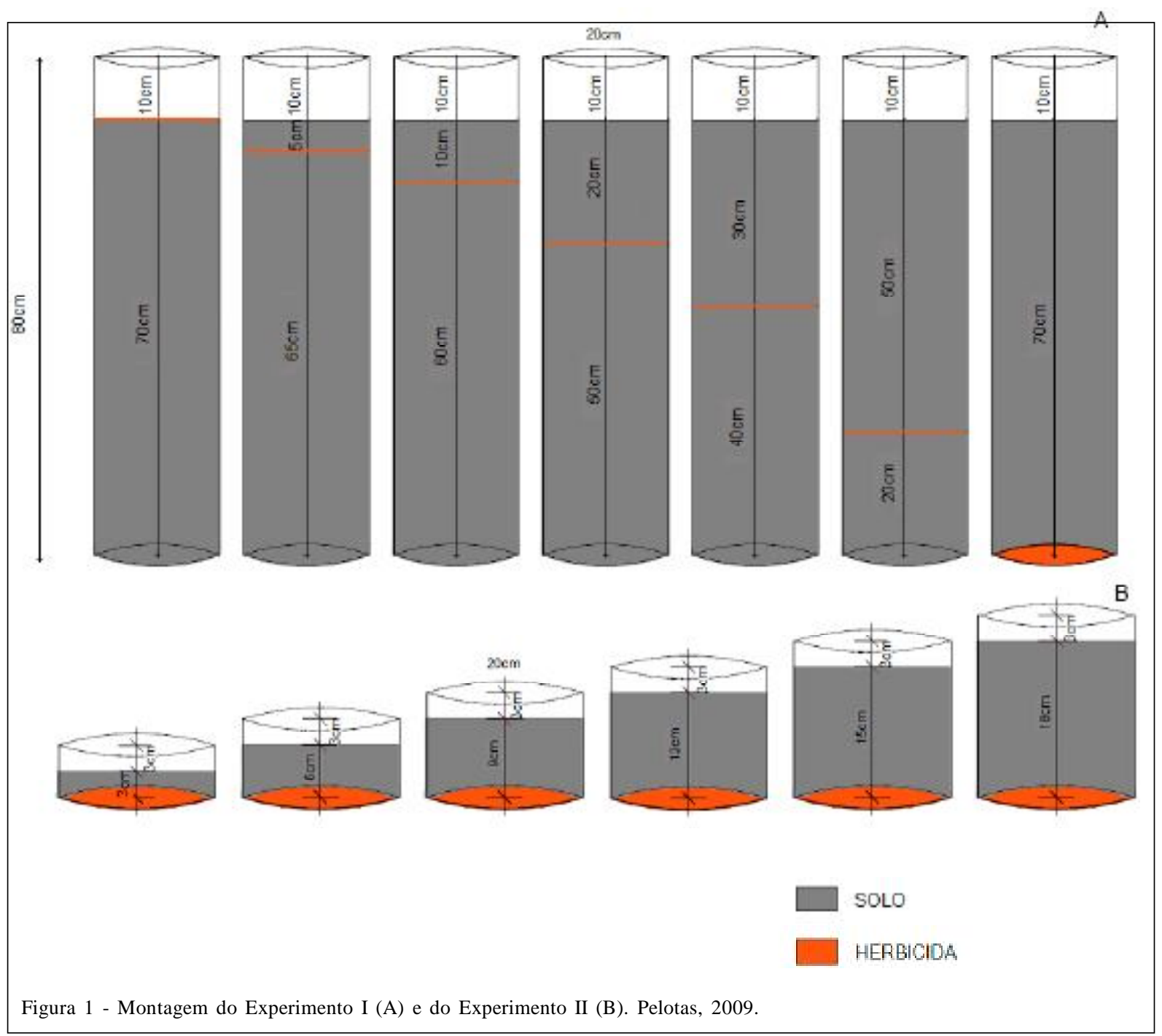

da semeadura e foram utilizados o equivalente a $350 \mathrm{~kg}$ ha $^{-1}$ da formulação 5-22-22 (N-P-K). A adubação nitrogenada em cobertura foi aplicada na forma de ureia e parcelada em duas épocas: $70 \mathrm{~kg} \mathrm{ha}^{-1}$ de $\mathrm{N}$ no estádio $\mathrm{V}_{4}$ e $40 \mathrm{~kg} \mathrm{ha}^{-1}$ de $\mathrm{N}$ no estádio $\mathrm{R}_{0}$ (COUNCE et al., (2000). Foram avaliadas a fitotoxicidade dessa mistura de herbicidas nas plantas de arroz aos 14, 28 e 42DAE (dias após a emergência das plântulas), sendo atribuídas notas expressas em percentagem variando de zero a 100, para ausência e presença de plantas mortas, respectivamente. Foi determinada também a massa da matéria seca da parte aérea das plantas (gramas) aos 50DAE, e as amostras foram secas em estufa com ar forçado, a $60^{\circ} \mathrm{C}$, até peso constante.

$\mathrm{O}$ experimento II foi conduzido no ano agrícola de 2009/10 e foi utilizado o mesmo delineamento experimental do Experimento I, porém as profundidades de localização do herbicida no solo foram de 3, 6, 9, 12,
15 , e $18 \mathrm{~cm}$ e a dose do herbicida aplicada foi equivalente a $1,0 \mathrm{~L} \mathrm{ha} \mathrm{ha}^{-1}(12,56 \mu \mathrm{L})$. Para cada profundidade de localização do herbicida no solo, atribuiu-se um tratamento testemunha (sem a aplicação do herbicida). As profundidades de localização foram determinadas de acordo com os resultados de fitotoxicidade obtidos no Experimento I.

Para a condução do experimento, foram utilizados vasos (baldes) plásticos $(8,0 \mathrm{~L})$, os quais foram cortados na altura correspondente a cada tratamento, sendo acrescidos mais $3,0 \mathrm{~cm}$, para que a lâmina de água fosse formada (Figura 1B). A aplicação dos tratamentos foi realizada conforme metodologia descrita para o Experimento I, porém o solo tratado com o herbicida foi colocado na base de cada vaso, que foram preenchidos com solo até a altura correspondente a cada tratamento. Esse procedimento foi realizado com o objetivo de evitar a lixiviação do 
herbicida, constituindo-se de um ajuste da metodologia adotada.

O solo, a adubação, a semeadura do arroz e o desbaste de plantas foram os mesmos descritos no Experimento I. Avaliou-se a fitotoxicidade do herbicida aos sete, 14, $21 \mathrm{e}$ 28DAE, a produção de massa da matéria seca (gramas por vaso) e a estatura de plantas aos 32DAE. Os dados obtidos foram analisados quanto ao cumprimento das pressuposições do modelo matemático e submetidos aos procedimentos de análise da variância e regressão polinomial, sendo utilizada equação exponencial de dois parâmetros.

\section{RESULTADOS E DISCUSSÃO}

No experimento I, em geral, a fitotoxicidade foi mais intensa nos tratamentos em que o herbicida foi localizado próximo da superfície do solo (Figura 2). Nas avaliações aos 28 e 42DAE, a fitotoxicidade no arroz foi maior nos tratamentos em que o herbicida foi alocado a 5 e $10 \mathrm{~cm}$, enquanto que, na alocação do herbicida a $20 \mathrm{~cm}$ da superfície, os sintomas de fitotoxicidade foram perceptíveis apenas aos 14DAE. Provavelmente, isso se deve ao maior tempo de recuperação da planta nas avaliações aos 28 e 42DAE, as quais podem ter emitido novas folhas, recuperando seu desenvolvimento, ou então, pela lixiviação do herbicida a maiores profundidades. Estudos mostraram que esses herbicidas apresentam movimento vertical ao longo do perfil do solo, e de 80 a $90 \%$ do produto aplicado pode se concentrar entre 10 e $20 \mathrm{~cm}$ do perfil do solo, permanecendo nessa faixa do perfil do solo por períodos longos (LOUX \& REESE, 1993), pois apresenta baixa taxa de degradação em condições anaeróbicas (MANGELS, 1991).

Para a massa da matéria seca da parte aérea, constatou-se comportamento similar ao observado para fitotoxicidade. Nos tratamentos em que o herbicida foi alocado superficialmente (0 a $20 \mathrm{~cm})$, ocorreu menor produção de massa seca pelas plantas (Figura 2D).

Assim como no Experimento I, observou-se que a fitotoxicidade da mistura desses herbicidas nas plantas foi maior nos tratamentos em que o produto foi alocado próximo da superfície do solo nos vasos (Experimento II, Figura 3). Esse comportamento se intensificou com o passar do tempo, provavelmente pelo fato de o sistema radical do arroz ficar em contato

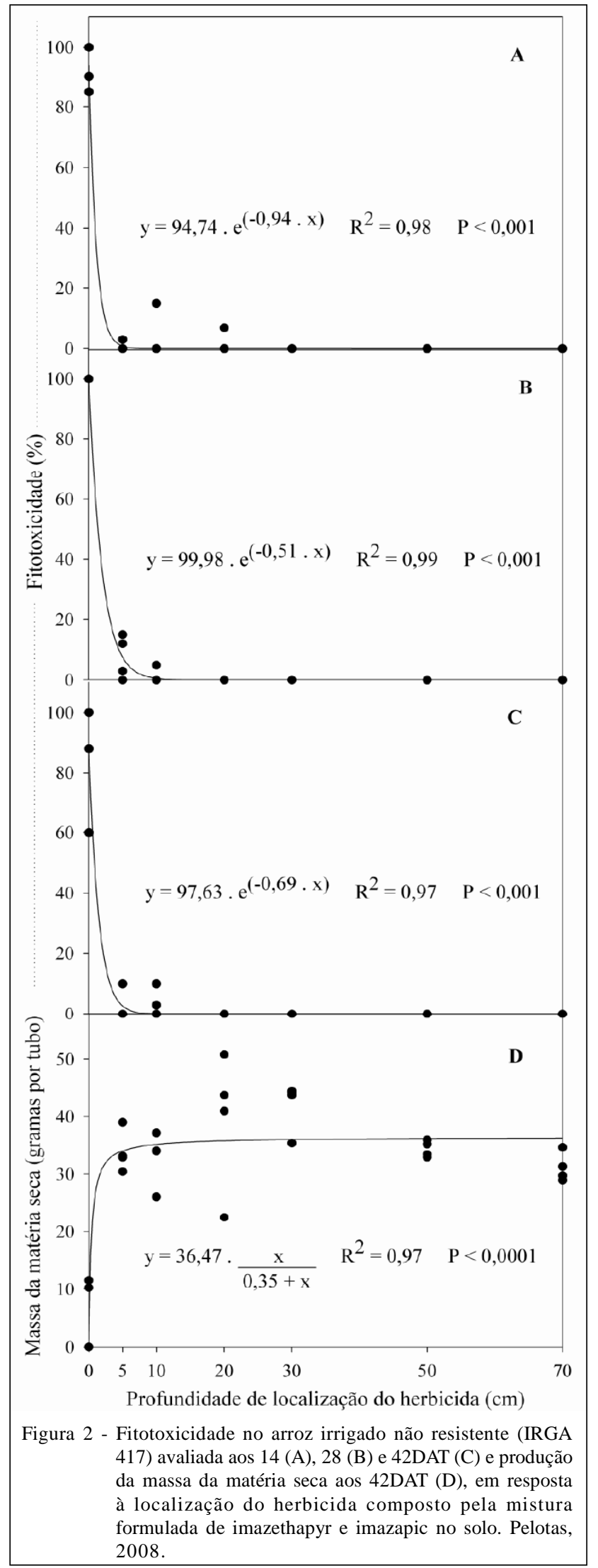

Ciência Rural, v.40, n.9, set, 2010. 


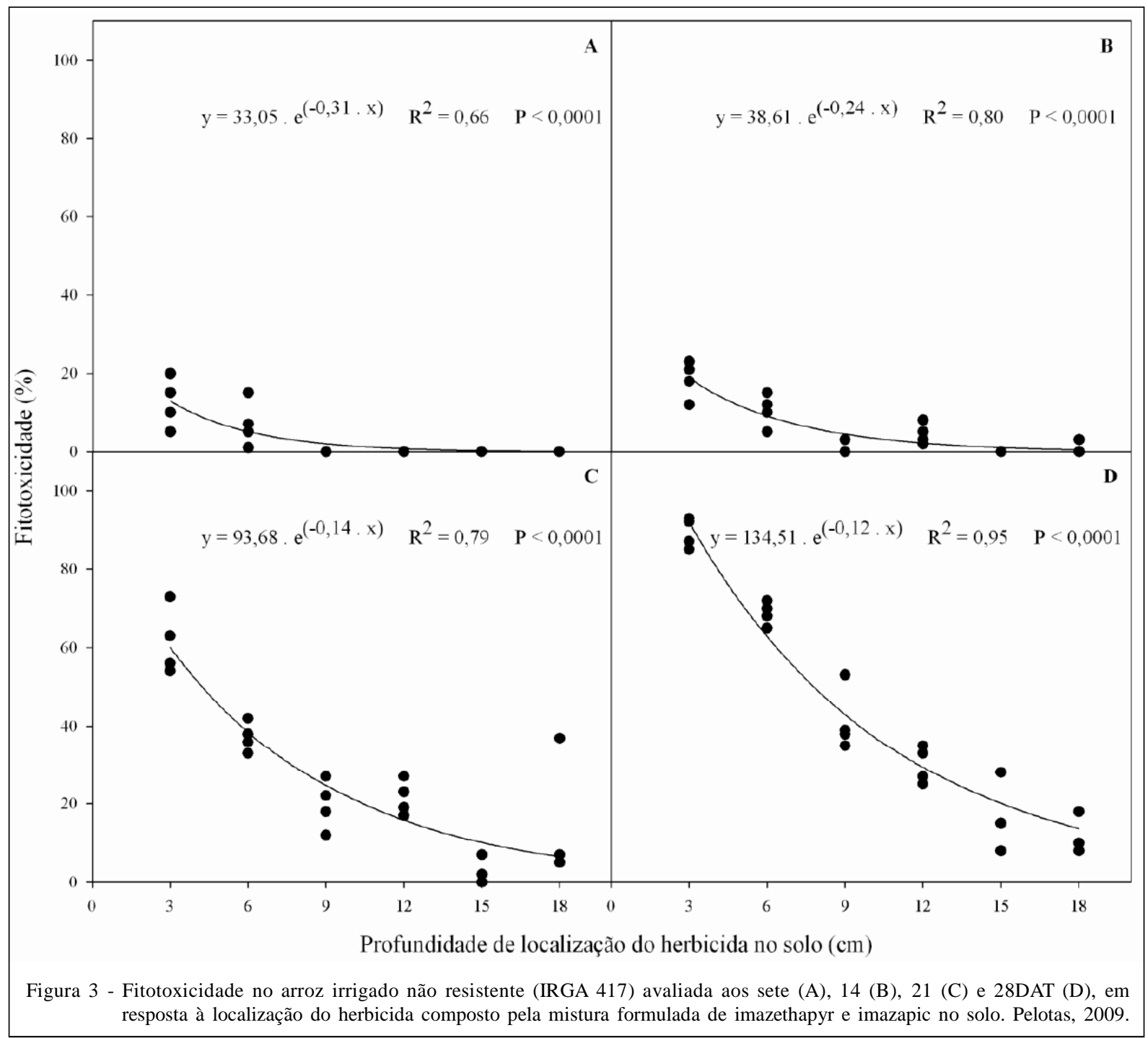

direto com os herbicidas desde a emergência das plântulas, período em que são mais sensíveis aos herbicidas.

$\mathrm{Na}$ figura $3 \mathrm{~A}$, somente foi observada fitotoxicidade nos tratamentos em que a mistura dos herbicidas foi alocada na região próxima da superfície do solo (3 a $6 \mathrm{~cm}$ ). Por outro lado, a ausência da fitotoxicidade em maiores profundidades no solo se deve provavelmente ao pequeno desenvolvimento das raízes que ainda não haviam atingido as maiores profundidades nos vasos, diminuindo assim a absorção dos herbicidas. Esse comportamento também pode ser atribuído ao fato de que nessa primeira avaliação o solo ainda não havia sido alagado. Sabe-se que a umidade do solo é fator importante na biodisponibilidade das imidazolinonas, pois influencia a sorção desses herbicidas, atuando como meio para a difusão das moléculas para os coloides adsorventes (EHLERS; LOIBNER, 2006). Em condições de solo saturado, a dessorção é favorecida devido à competição das moléculas do herbicida e da água pelos sítios de sorção do solo, ocasionando maior diluição desses herbicidas (AVILA et al., 2005). Assim, após o alagamento, o herbicida dessorve e se desloca para a solução, tornando-se mais disponível às plantas, comportamento observado nas avaliações posteriores ao alagamento (Figuras 3C e 3D), pela intensificação da fitotoxicidade nas maiores profundidades de alocação do herbicida.

A fitotoxicidade aos 21 e 28DAE (Figuras $3 \mathrm{C}$ e D) foi mais intensa nos tratamentos em que o herbicida foi alocado superficialmente, provocando supressão no desenvolvimento das plantas. Em contrapartida, para os tratamentos em que o herbicida 
encontrava-se em maiores profundidades, a fitotoxicidade nas plantas de arroz foi menos intensa. Acredita-se que esse comportamento se deve ao estádio de desenvolvimento mais adiantado e também ao maior potencial de recuperação das plantas no momento que as raízes atingem determinada profundidade no solo que não promova danos expressivos.
A maior redução de estatura de plantas foi observada no tratamento em que o herbicida foi alocado na profundidade de $3,0 \mathrm{~cm}$ (Figura 4A). Estatura decorrente da ação de imidazolinonas também foi encontrada em trabalhos realizados por AGOSTINETTO et al. (2001), que avaliaram o efeito residual do herbicida imazapir aplicado em canais de irrigação sobre a arroz com reflexo negativo na redução

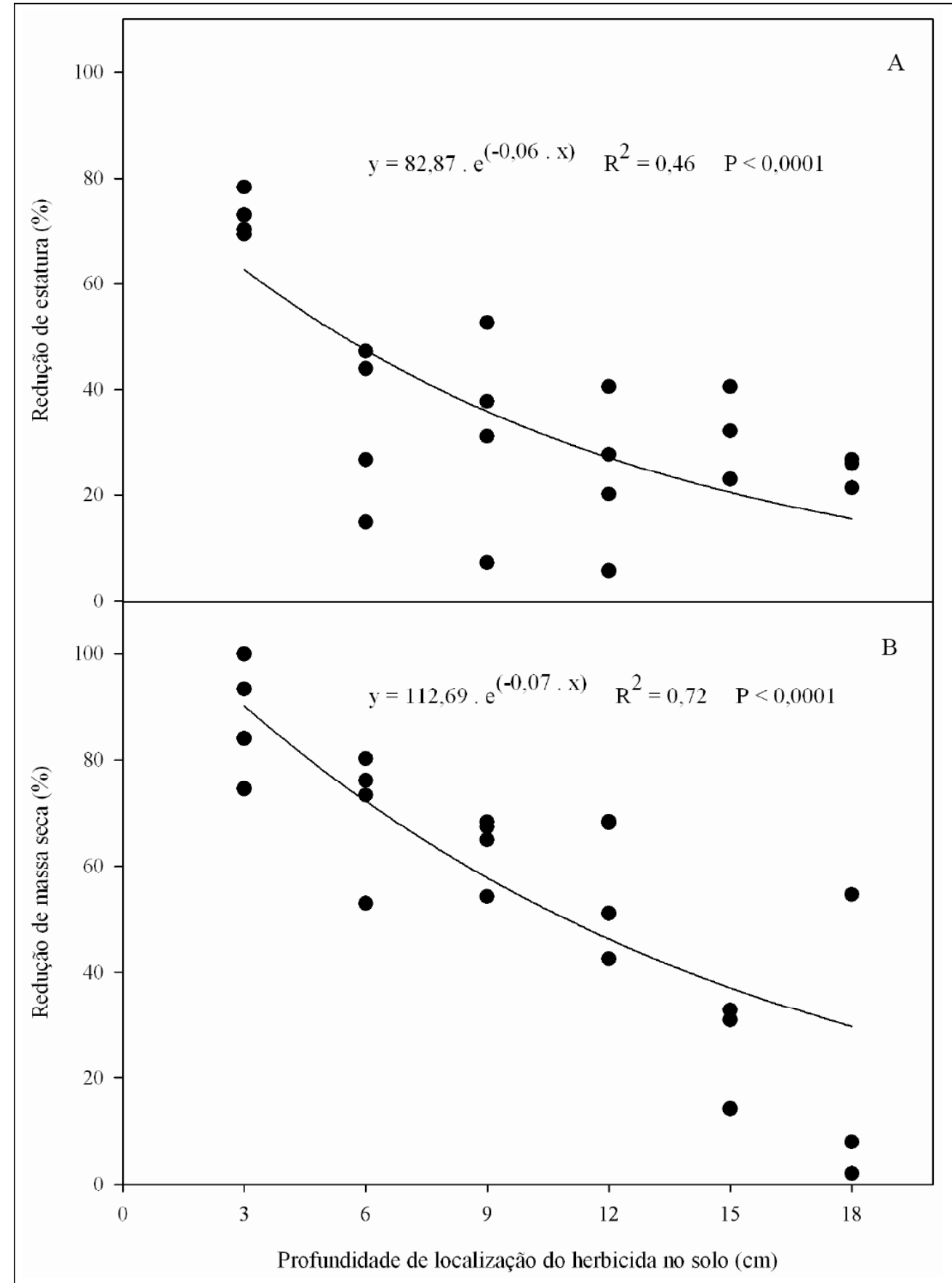

Figura 4 - Redução da estatura (A) e da massa da matéria seca (B) no arroz irrigado não resistente (IRGA 417). Pelotas, 2009. 
de estatura, no comprimento radical e na produção de matéria seca de raízes e da parte aérea. Já para a redução de massa seca (Figura 4B), o resultado foi semelhante aos encontrados para fitotoxicidade (Figura 3); e foram similares aos encontrados por KRAEMER et al. (2009), os quais, avaliando a persistência no solo da mistura formulada de imazetapir com imazapique, concluíram que, além de resultar em redução de massa da matéria seca produzida, também reduz o estande e a estatura de plantas, o perfilhamento e o número de panículas, porém sem afetar a produtividade de grãos.

Com base nos resultados, pode-se inferir que a profundidade de localização da mistura formulada de imazetapir com imazapique no solo é um fator de seletividade e pode explicar diferenças do efeito do residual dos herbicidas observados em diferentes condições de cultivo. Isso porque, em maiores profundidades no solo, o herbicida está menos sujeito a processos de degradação, tornando-se mais persistente no ambiente e, consequentemente, promovendo uma maior supressão no desenvolvimento das plantas.

\section{CONCLUSÃO}

O herbicida resultante da mistura formulada de imazetapir com imazapique alocado próximo à superfície do solo causa fitotoxicidade em genótipos de arroz não resistente, porém, quando em profundidades maiores que $20 \mathrm{~cm}$ da superfície do solo, não prejudica o desenvolvimento de genótipos de arroz não resistentes a essa mistura de herbicidas.

\section{REFERÊNCIAS}

AGOSTINETTO, D. et al. Ação residual do herbicida imazapyr aplicado em canal de irrigação sobre a cultura do arroz. Revista Brasileira de Agrociência, v.7, n.3, p.181-188, 2001.

AVILA, L.A. et al. Efeito da umidade do solo na sorção e disponibilidade de imazetapir em três solos. In: CONGRESSO BRASILEIRO DE ARROZ IRRIGADO, 4.; REUNIÃO DA CULTURA DO ARROZ IRRIGADO, 26., 2005, Santa Maria, RS. Anais... Santa Maria: UFSM, 2005. p.190-193.

COUNCE, P. et al. A uniform, objective, and adaptive system for expressing rice development. Crop Science, v.40, n.2, p.436-443, 2000.

EHLERS, G.A.C.; LOIBNER, A.P. Linking organic pollutant (bio)availability with geosorbent properties and biomimetic methodology: A review of geosorbent characterisation and (bio) availability prediction. Environmental Pollution, v.141, n.3, p.494-512, 2006. Disponível em: <http://www.sciencedirect.com/ science?_ob=ArticleURL\&_udi=B6VB 5-4HC6M 28 $2 \& \_$user $=10 \&$ \&_coverDate $=06 \% 2 \mathrm{~F} 30 \% 2 \mathrm{~F} 2006 \& \_$rdoc $=1 \&$ fmt $=$ high $\&$ _orig=search\&_sort $=\mathrm{d} \& \_d o c a n c h o r=\&$ view $=\mathrm{c} \& \_s e a r c h S t r I d=1$ $285609555 \& \_$rerunOrigin $=$scholar.google \&_acct $=$C000050221\& _version $=1 \&$ \&urlVersion $=0 \& \_u s e r i d=10 \& \mathrm{md} 5=32 \mathrm{c} 3 \mathrm{e} 16691 \mathrm{c} 3 \mathrm{f} 1 \mathrm{f}$ fc266a49f291eccd5>. Acesso em: 9 out. 2009. doi:10.1016/ j.envpol.2005.08.063.

HOLLAWAY, K.L. et al. Persistence and leaching of imazethapyr and flumetsulam herbicides over a 4-year period in the highly alkaline soils of south-eastern Australia. Australian Journal of Experimental Agriculture, v.46, n.5, p.669-674, 2006. Disponível em: <http:// www.publish.csiro.au/?paper=EA04223>. Acesso em: 7 nov. 2008. doi: 10.1071/EA04223.

INSTITUTO RIO GRANDENSE DO ARROZ - IRGA. Uso desordenado do Clearfieldpode comprometer a tecnologia. Revista Lavoura Arrozeira, v.56, n.445, p.21-23, 2008.

KRAEMER, A.F. et al. Lixiviação do imazethapyr em solo de várzea sob dois sistemas de manejo. Ciência Rural, v.39, n.6, p.1660-1666, 2009. Disponível em: < http://www.scielo.br/ scielo.ph p s cript = sci_arttext \& pid=S 0103 $84782009000600005 \& \operatorname{lng}=$ pt\&nrm=iso $>$. Acesso em: $12 \mathrm{dez}$. 2008. doi: 10.1590/S0103-84782009005000119.

LOUX, M.M.; REESE, K.D. Effect of soil pH on adsorption and persistence of imazaquin. Weed Science, v.40, n.3, p.490496, 1993. Disponível em: < http://www.jstor.org/pss/4045295>. Acesso em: 5 maio, 2009.

MANGELS, G. Behavior of the imidazolinone herbicides in soil: a review of the literature. In: SHANER, D.L.; O'CONNOR, S.L. (Ed.). The imidazolinone herbicides. Boca Raton: CRC, 1991. p.191-209.

MARCHESAN, E. et al. Carryover of imazethapyr and imazapic to nontolerant rice. Weed Technology, v.24, n.1, p.6-10, 2010. Disponível em: < http://wssa.allenpress.com/perlserv/ ?request $=$ get - document $\&$ doi $=10.1614 \% 2$ FWT-0 8 153.1\&ct=1>. Acesso em: 12 jan. 2010. doi: 10.1614/WT$08-153.1$

SANTOS, F.M. et al. Controle químico de arroz-vermelho na cultura do arroz irrigado. Planta Daninha, v.25, n.2, p.405412, 2007. Disponível em: <http://www.scielo.br/ scie lo.php? script $=$ sci_arttext \& pid = S $0100-$ $83582007000200022 \& \operatorname{lng}=p t \& n r m=i s o>$. Acesso em: 17 jun. 2009. doi: 10.1590/S0100-83582007000200022.

VILLA, S.C.C. et al. Arroz tolerante a imidazolinona: controle do arroz vermelho, fluxo gênico e efeito residual do herbicida a culturas sucessoras não tolerantes. Planta Daninha, v.24, n.4, p.761-768, 2006. Disponível em: <http://www.scielo.br/ s c i e lo.php ? script = s ci_arttext \& pid=S $0100-$ $83582006000400017 \& \operatorname{lng}=$ pt\&nrm=iso>. Acesso em: 17 ago. 2009. doi: 10.1590/S0100-83582006000400017.

ZHANG, W. et al. Effect of rotational crop herbicides on water- and dry-seeded Oryza sativa. Weed Science, v.48, n.6, p.340-345, 2000. Disponível em: <http://wssa.allenpress.com/ perlserv $/$ ? request $=$ get - pdf \&doi $=10.1614 \% 2$ F0043$1745 \% 282000 \% 29048 \% 5 \mathrm{~B} 0755 \% 3 \mathrm{AEORCHO} \% 5 \mathrm{D} 2.0 . \mathrm{CO} \% 3 \mathrm{~B} 2>$. Acesso em: 20 set. 2009. doi: 10.1614/00431745(2000)048[0755:EORCHO]2.0.CO;2. 